\title{
Writing Scientific Journal Manuscripts in English
}

\author{
Clinton C. Shock ${ }^{1,5}$ \\ Malheur Experiment Station, Oregon State University, 595 Onion Avenue, Ontario, OR 97914 \\ Myrtle P. Shock ${ }^{2}$ \\ Anthropology and Archaeology Program, Universidade Federal do Oeste de Pará, Câmpus Amazônia, Avenida \\ Mendonça Furtado 2946, Bairro Fátima, CEP 68040-050 Santarém, Pará, Brazil
}

Candace B. Shock ${ }^{3}$

Scientific Ecological Services, 1059 Southwest 2nd Avenue, Ontario, OR 97914

\author{
Stuart R. Reitz ${ }^{4}$ \\ Department of Crop and Soil Science, Oregon State University, Malheur County Extension, 710 Southwest \\ 5th Avenue, Ontario, OR 97914
}

Additional index words. scientific writing, manuscript preparation, English proficiency, international journals

\begin{abstract}
With the intensification of horticultural research around the world, increasing numbers of scientific manuscripts are being written in English by authors whose primary language is not English. English has become the standard language of science, and English language manuscripts are readily accessible to the global scientific community. Therefore, non-native English speakers are encouraged to publish appropriate studies in English. Reviewers of manuscripts written in English by non-native speakers are encouraged to focus on scientific content and to provide constructive criticisms to facilitate the international exchange of information. Problems associated with writing scientific manuscripts in English can impede the publication of good science in international journals. This article describes problems in horticultural manuscripts that are often encountered by authors who are non-native English speakers and provides suggestions and resources to overcome these problems. References have been selected that provide clear help for authors in horticulture and other plant sciences.
\end{abstract}

Scientists whose native language is not English often want to publish the outcomes of their research in journals in English, because English has become the predominant international language of science (Drubin and Kellogg, 2012; Garfield, 1967; Meneghini and Packer, 2007). Writing scientific manuscripts is difficult for almost everyone, but the structure of scientific manuscripts in English can be particularly difficult for non-native English speakers (Benson et al., 2010; Moreno et al., 2012). The summary presented here addresses normal expectations for the structure of scientific journal manuscripts and specific problems encountered by non-native English speakers based on our experience gained as reviewers. Some of the items covered here apply to the writing of any scientific manuscript. Many points are specific to writing in English. In addition to providing guidance to authors, this summary report may be helpful to advisers, mentors, and reviewers in knowing what to look for in evaluating a paper, and in giving constructive criticism for its improvement.

Publishing research does not begin once a project is complete and authors start to

Received for publication 11 Dec. 2015. Accepted for publication $22 \mathrm{Feb} .2016$

We thank Jay Noller, William Braunworth, and Erik Feibert of Oregon State University and four anonymous reviewers for constructive comments that have improved this manuscript.

${ }^{1}$ Director and Professor.

${ }^{2}$ Assistant Professor.

${ }^{3}$ Technical Writer.

${ }^{4}$ Professor and Extension Faculty.

${ }^{5}$ Corresponding author. E-mail: clinton.shock@ oregonstate.edu.

This is an open access article distributed under the CC BY-NC-ND license (http://creativecommons. org/licenses/by-nc-nd/4.0/). consider whether and where they will publish the work. Many of the essential tasks necessary to publish research occur before a research project is initiated. Prospective authors must focus their research projects on unresolved questions in the scientific and practical world and read the pertinent literature in that scientific field. A prospective author learns what others hypothesize to be answers to a scientific question and what methods have been considered to be adequate approaches to the research question. Then a prospective author can generate a new hypothesis and adopt statistically valid methods to address the question. The work of other researchers helps to provide ideas about valid methods in the field of science. If the author wishes to publish in English, the pertinent literature to review in research planning before initiating a new project should include relevant journal articles in English. The effort of writing the introduction and discussion of a manuscript is simplified by prior familiarity with the pertinent work, the procedures, the use of specialized terms in English, and the findings of others.

\section{Why Publish in English?}

Publishing in English immediately increases the visibility of a manuscript because of the predominance of English in scientific literature (Drubin and Kellogg, 2012). All scientific research and reports should be of good quality, but realistically not all work is of the same quality. Because manuscripts in English will have exposure to a larger audience, it is important that the work be of high quality. Manuscripts should not have questionable methods or questionable statistical analyses. Publishing research results in English helps the authors become part of the international scientific dialog.

\section{Manuscripts That Should Be Published in English}

Basic science that is on the forefront of knowledge and that will have wide interest should be published in English, regardless of where in the world it has been conducted. Also, practical applied research that is designed to provide answers to problems of broad geographic interest should be published in English. Consider the scope of the practical problem that is addressed. If the problem and results are international in scope, the manuscript should be published in English. If research results are regional (a local application of a well-known phenomenon), it is not as important that they be published in English. Publishing in a "native" language journal can make the locally important information more accessible to the relevant audience than publishing the manuscript in English.

Everyone wants to publish their manuscript in a high impact journal, but not every manuscript warrants publication in a high impact journal. There is nothing wrong with that. To publish in journals with high impact values requires planning research to answer significant research questions. It is difficult to address such important research questions using appropriate experimental methods that provide definitive conclusions.

\section{General Considerations in Preparing the} Manuscript

Follow the journal's format. The idea of following the journal's format should be 
self-evident. Yet, many manuscripts are prepared without considering the journal's format. The format may specify the headings of the different sections, the spacing between sentences, the reference citation format, how citations appear in the text, or other items important to that journal. For example, the American Society for Horticultural Science has instructions for authors and a style manual online (Anonymous, 2015a, 2015b). Style manuals are available that have wide applicability (Chicago Editorial Staff, 2010; Council of Science Editors, 2014).

Translating manuscripts into English. Translation services may do a good job of converting a foreign language into English; however, grammar, word use, and technical concepts deserve special attention. Translation services cannot be expected to know the proper terminology for specialized technical terms. A literal, word-for-word translation will not capture the specific terms used in any field of science. Beyond the translation services, someone knowledgeable about the technical terms in the specific field of science needs to review and revise the manuscript before its submission. Special resources with emphasis on some types of technical terms used in horticulture are available (Table 1).

\section{Sentence and Paragraph Structure}

Sentence structure needs to follow that used in English. Manuscripts translated from other languages into English and submitted to English language journals often retain partial sentence structure of the original language. These grammatical inconsistencies need to be corrected, preferably before submission, because they may inadvertently alter the intended meaning of the authors. Informal review by a competent native English speaker can correct most of these problems.

Sentences in scientific manuscripts in English are direct (Strunk and White, 1999). Sentences are relatively short and concise. Avoid compound sentences, those with multiple parts or extensive dependent clauses. If a long sentence can be divided in two, divide it. Long sentences with many parts and dependent clauses (so called "run-on" sentences) are not acceptable. One clue that a sentence needs to be divided is if it needs many commas to be intelligible.

The placement of descriptive phrases in a sentence can modify the sentence's meaning. If a descriptive phrase applies to the complete sentence, it usually is the first part of the sentence. The placement of descriptive phrases of times or dates is especially important. Locations of research are also placed at the beginning of a sentence if they also apply to the complete sentence.

The first sentence of a paragraph in a scientific manuscript in English introduces the subject of the paragraph. The introductory sentence must be written so that the reader only learns about the details of the subject later in the paragraph, and the paragraph should remain focused on the subject introduced in the first sentence.

\section{Use of Words}

Specialized words. While reviewing the scientific literature related to a research project before initiating research, learn the specialized words and terms used in that field of science. Know their meanings so that they can be used correctly in writing.

Word use meaning. Consult a dictionary to resolve doubts about the meaning of a word. If the word being used does not precisely match the meaning that needs to be communicated,

Table 1. Special online resources for authors (accessed 26 Mar. 2016).

\section{Terminology databases}

Thesaurus.com: http://www.thesaurus.com/

Acronyms and abbreviations: http://www.acronymfinder.com/

Merriam-Webster online dictionary: http://www.merriam-webster.com/

Dictionary.com: http://dictionary.reference.com/

OneLook Dictionary Search: http://www.onelook.com/

Taxonomy databases

American Phytopathological Society common names of plant diseases: http://www.apsnet.org/ publications/commonnames/Pages/default.aspx

Entomological Society, common names of insects and related organisms: http://www.entsoc.org/pubs/ common_names

U.S. Department of Agriculture, National Agricultural Library Catalog (AGRICOLA) (books/journals): http://agricola.nal.usda.gov/

International Committee on Taxonomy of Viruses: http://ictvonline.org/index.asp and http://ictvonline.org/ virusTaxonomy.asp

International Plant Names Index: http://www.ipni.org/index.html

U.S. Department of Agriculture, ARS, GRIN fungal database site: http://nt.ars-grin.gov/ fungaldatabases/index.cfm

U.S. Department of Agriculture, NRCS Plants Database: http://plants.USDA.gov

U.S. Department of Agriculture National Plant Germplasm System, Advanced Query of GRIN TAXONOMY Species Data plant taxonomy: https://npgsweb.ars-grin.gov/gringlobal/taxon/ taxonomysearch.aspx

U.S. Plant Variety Protection: http://www.ars-grin.gov/cgi-bin/npgs/pvp/pvplist.pl

Other resources

Online encyclopedia: http://www.encyclopedia.com/

Duke University Graduate School exercises and explanation of scientific writing: https://cgi.duke.edu/ web/sciwriting/index.php

I am. You are. It is. They are.

It has. They have.

It harvests. They harvest.

Although English verbs change with the subject, the changes are often irregular (Day and Gastel, 2011) and do not necessarily follow specific verb change patterns that are common in Latin root languages. In English, there is a stated subject for each verb, except in the imperative tense. In English, the verb does not contain an implicit understood subject.

Adverbs. Differences in results need to be described in objective, quantitative terms. Do not describe differences using subjective terms. Examples of subjective adverbs are mainly, nearly, obviously, very, and convincingly. Any adverb that is not needed for comprehension of the topic under discussion should be eliminated. Avoid unnecessary flowery adverbial phrases.

Personal pronouns. The words I, my, mine, we, our, and ours are generally not used in scientific manuscripts. For example:

$W e$ plowed the field. Change to "The field was plowed."

This was the last measurement of our trial. Change to "This was the last measurement of the trial." 
Articles and prepositions. The articles $a$, an, and the are difficult to use correctly. Also the prepositions in, on, of, with, to, and for are difficult to use correctly. It is advisable to have a native speaker familiar with English writing, read the text, and make any necessary corrections.

Capitalization. Capital letters are reserved for the formal name of an entity or person. For example, Gansu Province, China, and San Francisco, $C A$ are capitalized. Many places of research are formal entities. For example, the University of Pennsylvania and the Department of Horticulture are capitalized. Notice that the article the is not part of the formal name and is usually not capitalized. Scientific disciplines are not formal entities and are not capitalized. For example, the study of horticulture and a master's degree in soil science are not capitalized.

Spacing of words. Words always have a space between them. Following punctuations $(, . ;: ! ?)$ there is always a space in the text. There are always spaces before initial parentheses.

\section{Special Properties of Manuscript Parts}

The parts of a manuscript for the journals of the American Society of Horticultural Science are outlined in its style manual (Anonymous, 2015b). Day and Gastel (2011) provide detailed suggestions for each part of a scientific manuscript.

Here are some key points for the principal parts of a manuscript.

Abstract format. The first sentence or sentences of an abstract introduce the research question dealt with in the manuscript. The following sentence or sentences summarize the approach and methods used to investigate the research question and where the work was conducted. The abstract is completed by a concise statement of what was discovered without exaggeration or hyperbole.

The abstract is a miniaturized version of the entire journal manuscript. Both the abstract and the journal manuscript should be able to stand on their own without each other. The journal manuscript itself will contain an introduction describing the research question in greater detail and a referenced background. The journal manuscript has a detailed materials and methods section that provides information on the research approach. The discoveries and their relevance to the topic of the journal manuscript are described in detail in the results and discussion.

Both in the abstract and in the manuscript, avoid the excessive use of abbreviations. If an abbreviation will be used, the first time the term to be abbreviated is used, it is written out completely and followed by the abbreviation in parentheses.

The introduction. The introduction starts with a complete restatement of the research questions. It continues with background information on the research questions, what methods others have used to address the questions, and what they have discovered. It is far easier to write the introduction of a manuscript if the authors are very familiar with the state of contemporary science applied to the question before starting the research project. If one is unfamiliar with the most recent science addressing the research question, it will be difficult to make a clear justification for the research after it has been completed.

It is essential to present the findings of others in context. For the purpose of clarity, suppose that the research question of a hypothetical manuscript involves an innovation in the irrigation of onions (Allium cepa L.). Identification of the pertinent facts of each work cited (such as the plant species and cultivar, location, soil, climate, and irrigation system used) is essential for the reader to understand the appropriateness of the citation to the present work on onions.

The introduction also defines who will be able to use the results of the manuscript: theoretical or basic scientists, growers, industry, or others.

The introduction is written in the present tense.

Materials and methods. The materials and methods section completely describes the procedures so that others could duplicate the trial. All of the essential methods and statistical procedures should be included.

Research locations need to be identified. Recognition for research stations and institutes is critical because they make substantial contributions to many projects, and may struggle to retain their financial viability. Many experimental results can be generated on branch field stations, but without recognition they can encounter difficulty retaining their budget support.

Avoid naming treatments or processes in a way that introduces the appearance of bias or unnecessary levels of abstraction. Avoid treatment names that anticipate specific research outcomes or are otherwise subjective. For consistency, use the same name for the same treatment or method throughout the manuscript.

Identify key pieces of equipment, supplies, and materials that were indispensable for the procedures by their model or part number, manufacturer, and place of manufacture.

Use the past tense in the materials and methods section.

Results. Write the results using the past tense.

Report what happened. Confine the results to what was actually done and what was measured. Also, report what happened unexpectedly that was not controlled but could have a bearing on the experimental outcome.

Only include results that are relevant to answering the initial research question and omit information that is not relevant to the central focus of the study. Authors (not just non-native English speakers) often find a statistically significant result not directly pertinent to the original research question and then prolong the results and discussion sections of a manuscript by comparing their results with those of other studies, even when the result has no direct bearing on the subject of the manuscript.

Discussion. The discussion of the results from the work is written using the past tense. Discussion of the work of others is written in the present tense.

Like the results section above, the discussion must focus on the central research question. The discussion needs to consider alternative explanations for the results obtained. When comparing the current results with the results of prior research, provide adequate context for the research of others so that variations in outcomes can be compared. Subtle differences in methods or less subtle differences in plant materials, locations, climate, etc. can provoke remarkable differences in research outcomes. All of the different outcomes may be real and valid. Their contexts help provide an understanding of the differences in outcomes.

Be modest in promoting one's own results. Avoid sweeping statements beyond the true scope of the research at hand.

Tables and figures. Tables and figures should be understood even if they are separated from the text of the manuscript. Captions should be sufficiently descriptive for readers to understand the figures and tables without referring to the text. This means that all abbreviations that are used in a table or figure must be defined in the table or figure. As an alternative, sometimes it is easier to reduce the use of abbreviations in tables and figures. Figure and table legends should include keywords necessary to understanding their content. If a manuscript compares variables, such as treatments, crops, or locations, the figure and table legends should name the variable or combination of variables that are referred to in the figure or table.

Conclusions. The conclusions should highlight the research question and the approach taken to shed light on the question. Only summarize the main findings of the current work related to the research question. Do not mention statistically nonsignificant results, unless it was a surprise that they were not statistically significant and that is the point of mentioning them.

Do not mention conclusions from other projects or other parts of the same project. If they are important, another scientific manuscript should be written to describe them.

Acknowledgments, authors, and references. Individuals making substantial contributions to research should be recognized as coauthors of the manuscript. Essential technical staff may be coauthors, even if they do not write or revise the manuscript.

Only those works cited in the text should be included in the references. Every work cited in the manuscript is listed in the references.

Funding sources should be recognized by being named in the acknowledgments. 


\section{Plagiarism}

All parts of a manuscript need to be original and need to be written by the authors. In discussing the scientific literature, it may be difficult to restate a concept in a better or different way than someone else has already done, but rewording is essential. Providing a reference to the original source does not give authors license to copy someone else's words.

\section{Proofreading the Manuscript}

Before submitting a manuscript, read it over carefully to eliminate as many errors as possible. Control the text for grammar and spelling automatically in a word processor. Control the spacing between words, sentences, and terms in each sentence.

Examine the units in any mathematical equation. Make sure that the units in mathematical terms are correct and that they are consistent when used in an equation.

Compare the citations in the text and in the list of references to ensure that all citations in the text are listed in the reference section. Delete unused references from the reference list.

\section{Conclusions}

Writing scientific journal manuscripts in English is a demanding and exacting task. The task is even more challenging for scientists whose native language is not English. This article outlines general expectations of scientific manuscripts in horticulture and plant sciences and directs authors to additional resources that can assist them in understanding and overcoming the hurdles in manuscript preparation. Mentors and reviewers can be helpful in clearly advising authors of manuscript expectations and providing constructive suggestions.

\section{Literature Cited}

Anonymous. 2015a. Instructions for authors. American Society of Horticultural Science. $21 \mathrm{Feb}$ 2016. <http://c.ymcdn.com/sites/www.ashs.org/ resource/resmgr/Author_instruct_2014.pdf $>$.

Anonymous. 2015b. ASHS publication style manual American Society of Horticultural Science. $21 \mathrm{Feb}$ 2016. <http://c.ymcdn.com/sites/www.ashs.org/ resource/resmgr/files/style manual.pdf $>$.

Benson, P., T. Lang, M.A. Baynes, and W. Aribisala 2010. How are non-native-English-speaking authors coping with requirements to publish in English-language journals? Sci. Ed. $33: 189$.
Chicago Editorial Staff. 2010. The Chicago manual of style. 16th ed. University of Chicago Press, Chicago, IL.

Council of Science Editors. 2014. Scientific style and format: The CSE manual for authors, editors, and publishers. 8th ed. University of Chicago Press, Chicago, IL.

Day, R. and B. Gastel. 2011. How to write and publish a scientific paper. 7th ed. Greenwood, Santa Barbara, CA.

Drubin, D.G. and D.R. Kellogg. 2012. English as the universal language of science: Opportunities and challenges. Mol. Biol. Cell 23:1399.

Garfield, E. 1967. English-An international language for science. Info. Scientist 1:19-20.

Marlow, M.A. 2014. Writing scientific articles like a native English speaker: Top ten tips for Portuguese speakers. Clinics 69(3):153-157.

Meneghini, R. and A.L. Packer. 2007. Is there science beyond English? Initiatives to increase the quality and visibility of non-English publications might help to break down language barriers in scientific communication. EMBO Rpt. 8(2):112-116. doi:10.1038/sj.embor.7400906.

Moreno, A.I., J. Rey-Rocha, S. Burgess, I. LópezNavarro, and I. Sanchez. 2012. Spanish researchers' perceived difficulty writing research articles for English medium journals: The impact of proficiency in English versus publication experience. Ibérica 24:157-184.

Strunk, W. and E.B. White. 1999. The elements of style. 4th ed. Pearson Education, Inc., Boston, MA. 